\title{
TRANSPORT ENERGY EFFICIENCY ASSESSMENT ON THE BASIS OF THE LIFE CYCLE WITH THE ATTRACTION OF THE BARTINI TRANSFER ENTITY
}

\author{
Jurij Kotikov \\ Saint Petersburg State University of Architecture and Civil Engineering \\ Vtoraja Krasnoarmejskaja ul. 4, St. Petersburg, Russia \\ cotikov@mail.com
}

\begin{abstract}
A technique for assessing the transport energy efficiency on the basis of the life cycle is developed with the use of the Bartini Transfer entity.

Main elements of the technique are the following: 1) assertion of the necessity to correlate (compare) the amount of energy to the absolutized transfer of a transport object with the life-cycle Cumulative Energy Demand (CED); 2) selection of the Bartini Transfer entity (and the corresponding cell of the Bartini table) for the mentioned correlation; 3 ) use of the Tiguntsev model for calculations of the kinetic and potential energy for the motion of an absolutized transport object in the gravitational field; 4) construction of a diagram with axes Speed V and Specific CED; 5) carrying out of the analysis in the field of the V-CED diagram for the comparison of the amount of energy to the transfer of an absolutized transport object with the transport system CED for such transportation. A number of examples are given.
\end{abstract}

\author{
Keywords \\ Transport, squared speed, Bartini, Transfer, Tran, energy efficiency, life cycle.
}

\section{Introduction}

Let us make several statements which hold for the energy, economy and transport industries on the threshold of a historically new technological paradigm.

1. The transportation customer is keenly interested in the express delivery of the freight itself, but pays less attention to the means of transportation.

2. All resistances (air resistance, road resistance, etc.) depend on the squared speed of a vehicle.

3. It is the squared speed which determines the energy of object transfer and even processes of manufacturing transport system elements.

4. With the approach of a new technological paradigm, it becomes more and more important to take into account the speed of process implementation (or, more specifically, the squared speed).

5 . Since the early days, manufacturing of all items has been carried out due to the solar energy.

6 . The following question is relevant: what is the efficiency of the initial solar energy utilization in the industry, e.g., by a transport system?
7. To answer this question, it is reasonable to correlate the energy to the absolutized transfer of a target transport object in the Earth's gravitational field, in vacuum, under levitation conditions and in the absence of mechanical environmental resistances, on the one hand, with the fossil CED through the production chain up to and including the freight delivery to the consignee, on the other hand.

8. The correlation (comparison) of the amount of energy to the mentioned absolutized transfer of a transport object with the CED (according to the terminology of ISO 14040: 2006 and ISO 14044: 2006 standards for Life Cycle Assessment (LCA)) will allow establishing an indicator (index) for the energy efficiency of the transport system, the transport mode, the fleet of vehicles, an individual vehicle.

9. The amount of energy to the mentioned absolutized transfer of an object will play the role of the minimum minimorum idealized estimate. Technically, it is unattainable, but being abstract and unrelated to the specific transport mode, it can serve as the basis for obtaining comparative 
assessments of energy efficiency for operational groups of vehicles within transport modes and between them.

\section{Problems and methods}

The energy efficiency of the A system is the ratio of the value of $A$ useful services to the energy consumption of this A system. Usually both the output and the energy consumption are related to a period of time, which obviously leads to the elimination of time and yields the dimension "services per energy" such as $\mathrm{km} / \mathrm{kJ}$ for a vehicle, $\mathrm{kg} / \mathrm{kWh}$ for a waste disposal process, or kByte/Ws for an internet service (Hilty, 2009).

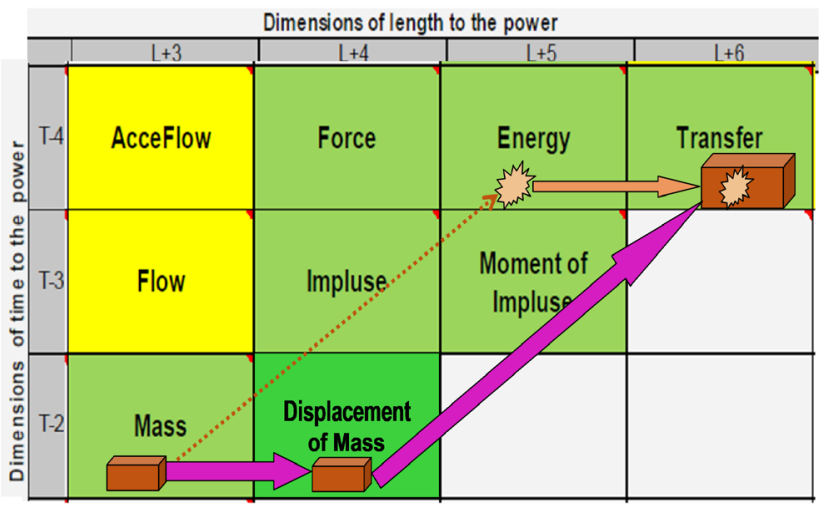

Figure 1. Part of matrix of physical laws as a canvas for analysis

Let $S$ be the service estimate at the system output, and $E-$ the system energy consumption. Then, the energy efficiency can be determined as $\mu=S / E$.

Let us note that according to this definition the energy efficiency differs from the efficiency (sometimes called the energy efficiency as well) defined in physics as $\eta=E_{\text {out }}$ / $E_{i n}$, where $E_{\text {out }}$ is the useful output energy of the system, and $E_{\text {in }}$ is the input energy (where these essences are of the same kind). Obviously, the $\eta$ efficiency is a special case of the $\mu$ energy efficiency. For computer systems, it is possible to assume $\eta=0$, as all energy is converted to heat in the end, while the purpose of these systems is not heat supply.

As for the transport sector, it shall be noted that the operation of a transport system (by analogy with a computer system) results in object transfer or, more precisely, rendering of services for the transfer of a target object to a certain customer. Thus, the energy efficiency of a transport system shall be determined by the following equation:

$\mu=\frac{S}{E}$

The objective of the author's studies (Kotikov, 2001, 2005a, 2005b, 2006, 2017a, 2017b) and the present study is to develop a new methodological approach to the assessment of the energy efficiency of transport and provided transport services considering the squared speed of the transport object delivery. This approach is related to the development of Robert Bartini's ideas on $L T$-systema- tization of physics laws on the basis of a pair of coordinate parameters Length $(L)$ - Time (T) (Bartini, 1965, 1974). The core of this approach is to form the ratio between the transferred transport output to the destination point (considering the squared speed of the freight transfer transfer service S) and the specific embodied energy consumption of the transport system for this freight transfer. Convergence of dimensionalities of two mentioned ratio variables is provided at the Transfer entity level with the dimensionality L6T-4 (Aleinikov, 2007) of Bartini $L T$-table.

Case studies considered in works (Kotikov, 2005b, 2017a and 2017b) by instances of freight delivery by a single-unit KamAZ-5320 vehicle with speeds of $40 \mathrm{~km} / \mathrm{h}$ and $60 \mathrm{~km} / \mathrm{h}$, and by a high-speed train with a speed of 120 $\mathrm{km} / \mathrm{h}$ showed low energy efficiency (in terms of the utilization of the total borrowed solar energy) of modern freight transportation: $\mu=0.05-0.16$.

In the present article, an attempt is made to strengthen the methodological approach in terms of terminology as well as through visual analysis tools. An important feature of the approach is the active use of the Life Cycle Assessment (LCA) concept for the transport system and carrying out of a design study covering energy consumption of the main functional constituent elements of the system: creation, technical support, working process (ISO 14040-2006 and 14044-2007).

A fragment of R. Bartini $L T$-table (Bartini, 1965) in the interpretation of A. Aleinikov (Aleinikov, 2007) serves as a methodological canvas for the study (Kotikov, 2017a, 2017b) and is given in Figure 1.

The upper branch in Figure 1 (Mass - Energy - Transfer) reflects the freight mass $M_{\text {net }}$ transfer to the composition of the transport carrier, thus, forming the mass $M_{\text {gross }}$ $=M_{\text {net }}+M_{\text {carr }}$. Here $M_{\text {carr }}$ is a specific part of the transport carrier mass, associated with the freight mass $M_{\text {net }}$. Hereinafter, the mass $M_{\text {gross }}$ with the energy consumption $E_{\Sigma}$ is transferred over distance $L$ to the destination point, thus, forming real value for Transfer $S_{\text {gross }}$ index.

Here $E_{\Sigma}=E_{\text {Emb }}+E_{\text {Supp }}+E_{\text {Input }}^{\text {gross }}$, where $E_{\text {Emb }}, E_{\text {Supp }}$ and $E_{\text {Input }}-$ utilization of specific parts of energy, respectively:

- embodied in the transport carrier and infrastructure;

- designed for technical support;

- input and directly consumed for transportation.

All three components are in shares associated with the mass $M_{\text {gross }}$ and transportation distance $L$.

The dashed line from Mass to Energy means a relation between the Demand (object mass transfer) and Supply (availability of transfer means and infrastructure with preliminary embodied energy, as well energy for support and input).

The lower branch in Figure 1 (Mass - Displacement of Mass - Transfer) represents a process of the formation of the ideal, illusory assessment of transport service Transfer $S_{\text {net }}$ (net-process) for abstract transfer of net-mass of the freight $M_{\text {net }}$ over distance $L$ at speed $V$. Strictly speaking, the Customer is interested in the implementation of these factors (it is almost not interested in the transfer of 
gross-mass $M_{\text {gross }}$, realized by an energy-intensive carrier under the conditions of the real transport system).

Transfer of the transport object itself is absolutized. The object is transferred from the initial to the final point with conditional consideration of energy consumption for overcoming of the Earth's gravitational field (proportional to the squared speed of the transfer). Everything connected with energy consumption for the manufacture of the transport carrier structure, erection of the traveling construct, overcoming of the carrier motion resistances, motion control, technical operation, etc. is put to the "upper branch" (with introduction of the above into the Energy cell).

This provides a possibility of numerical assessment of the correlation between the transport object transfer by means of real transport under real conditions and the conditional absolutized transfer of a transport object which is the utmost effective to the Earth's gravitational field.

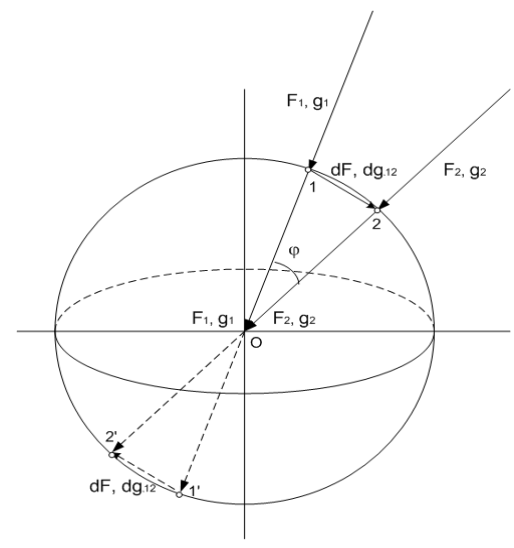

Figure 2. Model for the formation of the force required for the uniform motion of a body along the equipotential surface of the Earth's force field (Tiguntsev, 2014, 2015)

The ratio $\mu=S_{n e t} / S_{\text {gross }}$ characterizes the level of excellence of the carrier type in the existing technological paradigm within the scales of the development of solar energy by mankind.

A distinctive feature of the calculation for the specific embodied energy of the transport system using the author's method is the reduction of energy consumption for the life cycle of all system components to the life cycle of the transport carrier. Under consideration of the total mileage of the transport carrier within its life cycle, this provides a direct possibility to calculate energy consumption for the performance of a particular transportation.

To present and calculate the mentioned absolutized transfer of a transport object, let us use the model of S.G. Tiguntsev for the formation of a force required for the uniform motion of a body along the equipotential surface of the Earth's force field (Tiguntsev, 2014, 2015). For small areas of transfer and low-speed vehicles, the model represents the "horizontal movement". For high speeds and large areas (aviation, Hyperloop (http://www.spacex.com/ sites/spacex/files/hyperloop_alpha-20130812.pdf), space transport), the model is able to represent the motion along the equipotential surface. Such model flexibility is useful for a "seamless" analysis of the operation of the entire range of vehicles on a single canvas. Let us represent the model briefly.

The body with the mass $m$ experiences the gravity force $\boldsymbol{F}$ equal to the product of the mass $m$ by the gravity acceleration vector $\boldsymbol{g}$ (the boldface characters are vectors). In two separated points 1 and 2 of the Earth's surface, the body with the mass $m$ experiences gravity forces $\boldsymbol{F}_{1}$ and $\boldsymbol{F}_{2}$ equal to the product of the mass $m$ by the gravity acceleration vectors $\boldsymbol{g}_{1}$ and $\boldsymbol{g}_{\mathbf{2}}$, respectively, equal in magnitude (see Figure 2). The vectors $\boldsymbol{g}_{1}$ and $\boldsymbol{g}_{2}$ converge in the center of the Earth (point $O$ ) at an angle $\varphi$ to each other. The vectors of forces $\boldsymbol{F}_{1}$ and $\boldsymbol{F}_{2}$ are also equal in magnitude and converge in the center of the Earth at an angle $\varphi$ to each other. For illustrative purposes, the vectors are shown in the figure at a sufficiently large angle to each other, although this angle can be arbitrarily small.

Let us assume that, after the application of the force impulse, the body is in a state of the uniform motion along the "horizontal" surface of the Earth from point 1 to point 2 in the absence of braking effects of the surface and the air. The path between these points 1 and 2 is curvilinear (even in the smallest section) with a curvature radius equal to the radius of the Earth.

When the body moves uniformly from point 1 to point 2 , it permanently experiences the force equal to the difference of the $\boldsymbol{F}_{2}$ and $\boldsymbol{F}_{1}$ forces (after the transfer of the origin of the $\boldsymbol{F}_{2}$ and $\boldsymbol{F}_{1}$ vectors to the point 0 , for the transferred vectors $\boldsymbol{F}_{1}$ and $\boldsymbol{F}_{2}$ having the common point 0 , the rule of subtraction of vectors can be applied). The vector $\boldsymbol{d} \boldsymbol{F}$ equal to the difference of the vectors $\boldsymbol{F}_{2}$ and $\boldsymbol{F}_{1}$, represents a force, which being external relative to the body, acts from point 1 to point 2 and ensures the uniform motion of the body along the equipotential surface, in the absence of inhibiting factors, as long as desired. Thus, the force acting on a body with the mass $m$ is determined by the following equation:

$d F=m \cdot\left(g_{2}-g_{1}\right)$

In equation (2), the difference of vectors $d \boldsymbol{g}=\left(\boldsymbol{g}_{2}-\boldsymbol{g}_{1}\right)$ represents the acceleration, which is constantly provided by the force $\boldsymbol{d} \boldsymbol{F}$. The mentioned acceleration is related to the gravity acceleration, the only difference being that the gravity acceleration acts always, and the mentioned acceleration acts only from the moment when, after the force application, the body falls in a state of the uniform motion. Experiencing the force $\boldsymbol{d} \boldsymbol{F}$, the body is in a state of the uniform motion with the following speed:

$V=\left|g_{2}-g_{1}\right| \cdot \frac{R}{g} \cdot \Delta t$

Based on equation (3) at $\boldsymbol{\Delta t}=\mathbf{1}$ unit of time, it is possible to obtain the following equation: 
$\frac{|d g|}{\Delta t}=g \cdot \frac{V}{R}$

In the Tiguntsev model, a part of the potential energy of gravity is constantly converted into the kinetic energy of the body motion $K_{t g}$, which is determined as the product of the force $\boldsymbol{d} \boldsymbol{F}$ by the covered distance $(L)$ :

$K_{t g}=d F \cdot L$

After transformations of traditional theoretical mechanics, working equations are obtained. For the potential energy:

$E_{p}=A=m \cdot g \cdot L=m \cdot g \cdot V \cdot \Delta t$

where $A$ is gravitational work.

The kinetic energy of the body moving uniformly with a speed $\boldsymbol{V}$ is equal to the energy which the body received when speeding from zero to the speed of the uniform motion $\mathbf{V}$ :

$E_{k}=\frac{m \cdot V^{2}}{2}$

\section{Case Study}

Let us consider graphs of types of the required energy vs. the speed of the uniform absolutized motion, plotted according to equations (6) and (7).

As for our idealized object, the kinetic energy accumulates (blue curve in Figure 3 ) in the course of its acceleration as a result of the propulsive force impulse from the side of the leading element, with the transformation of the impulse into the object momentum. At the stage of deceleration, the kinetic energy returns to the leading element (with the full recovery for our idealized minimum minimorum scheme). Thus, the dependence of the potential energy on the speed of motion (red curve in Figure 3 ) remains as an estimate of the lower field boundary required for the energy transfer.

Because of the wide range of speeds $V$ of the transport modes under study and high values of energy consumption $E$, which are expected during the analysis, axes of the graph on a logarithmic scale are used (Figure 4).

Depending on the transport object (freight or passengers), the corresponding ordinate axis of the specific energy consumption shall be referred to: $\mathrm{MJ} / \mathrm{kmm}$ for freight traffic (the left axis), kWh/pkm for passenger traffic.

The selection of such dimensions is determined by the convenience of their recalculation and alignment with the mentioned axes, namely: with the assumption that 1 ton corresponds to a weight of 14 persons (71.43 kg/person), $1 \mathrm{kWhr} / \mathrm{pkm} \approx 50 \mathrm{MJ} / \mathrm{tkm}$.

The following vehicles are shown in Figure 4, for which information on the life-cycle CED is available:

1) KamAZ-5320 truck, speed $40 \mathrm{~km} / \mathrm{h}$ (Kotikov, 2006);

2) KamAZ-5320 truck, speed $60 \mathrm{~km} / \mathrm{h}$ (Kotikov, 2017a);

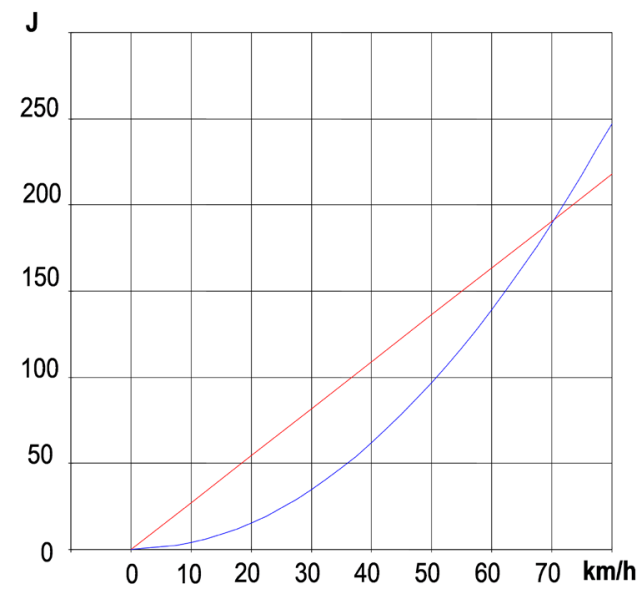

Figure 3. Graphs of energy vs. the rate of the uniform motion (vertical axis - energy, $\mathrm{kg} \cdot \mathrm{m}^{2} / \mathrm{s}^{2}$, horizon-

tal axis - the speed of the uniform motion, $\mathrm{km} / \mathrm{h}$ )

3) Freight train (Rail diesel/electric), speed $75 \mathrm{~km} / \mathrm{h}$ (Mithraratne, 2011);

4) 15-30 t trucks, speed $75 \mathrm{~km} / \mathrm{h}$ (Mithraratne, 2011);

5) 7.5-15 t trucks, speed $75 \mathrm{~km} / \mathrm{h}$ (Mithraratne, 2011);

6) 5-7.5 t trucks, speed $75 \mathrm{~km} / \mathrm{h}$ (Mithraratne, 2011);

7) Passenger car, speed $75 \mathrm{~km} / \mathrm{h}$ (Mithraratne, 2011);

8) Passenger train (Heavy Rail Transit (HRT)), capacity 35-350 passengers, speed $75 \mathrm{~km} / \mathrm{h}$ (Chester, 2010);

9) Bothnia Line freight train, speed $120 \mathrm{~km} / \mathrm{h}$ (Kotikov, 2017b);

10) Mercedes-Benz A passenger car (diesel), speed 120 km/h (Life Cycle, 2015);

11) Mercedes-Benz A passenger car (petrol), speed 120 km/h (Life Cycle, 2015);

12) Mercedes-Benz $S 400$ Hybrid passenger car, speed 120 km/h (Life Cycle, 2015);

13) Passenger car, capacity $1-5$ passengers, speed 120 km/h (Chester, 2010);

14) $\mathrm{CRH} 2$ passenger train, speed $250 \mathrm{~km} / \mathrm{h}$ (Zhou, 2014);

15) CRH3 passenger train, speed $350 \mathrm{~km} / \mathrm{h}$ (Zhou, 2014);

16) HS2 passenger train, speed $360 \mathrm{~km} / \mathrm{h}$ (Zhou, 2014);

17) TGV duplex passenger train, speed $330 \mathrm{~km} / \mathrm{h}$ (Zhou, 2014);

18) Passenger train (California High Speed Rail (CASHR)), capacity 120-1,200 passengers, $354 \mathrm{~km} / \mathrm{h}$ (Chester, 2010);

19) Maglev UK Ultraspeed train, speed $500 \mathrm{~km} / \mathrm{h}$ (Zhou, 2014);

20) B757-200 aircraft, speed $880 \mathrm{~km} / \mathrm{h}$ (Zhou, 2014);

21) B737-300 aircraft, speed $820 \mathrm{~km} / \mathrm{h}$ (Zhou, 2014);

22) B747-400 aircraft, speed 940 km/h (Zhou, 2014); 
23) Aircraft, capacity $24-120$ passengers, $820 \mathrm{~km} / \mathrm{h}$ (Chester, 2010).

\section{Discussion}

In Figure 4, two indicative lines are seen, which originated in Figure 3 and transitioned to Figure 4 with significant expansion of the speed range up to $1,000 \mathrm{~km} / \mathrm{h}$.

The blue parabola of the kinetic energy from Figure 3 transformed in logarithmic coordinates of Figure 4 into a straight line. Upon the transition, the red straight line of the potential energy slightly bent (typical for low speeds of less than $40 \mathrm{~km} / \mathrm{h}$, where both curves tend to zero).

The blue curve shows the level of energy required for the acceleration of the unit mass of a target object ( $1 \mathrm{t}$ of freight - on the left axis of ordinates, or 1 passenger on the right axis of ordinates). As we know, all kinetic energy received by a target object from a vehicle is returned to such vehicle at the stage of deceleration.

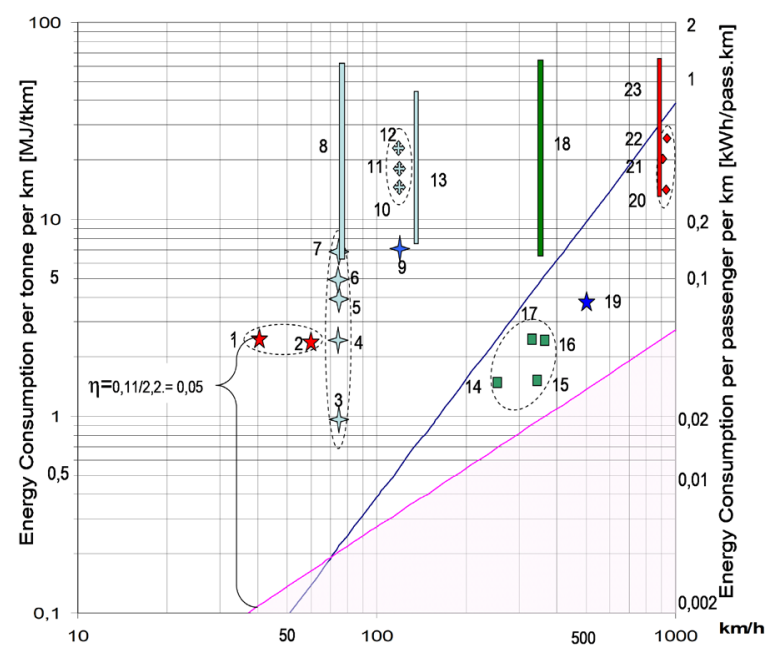

Figure 4. Location of vehicles in the $\mathrm{V}-\mathrm{E}$ graph

The potential energy does not return to the source of energy supply, i.e. our vehicle. Its level increases with the speed increase, according to the red curve, but this energy is continuously spent on the work of forces of the interaction with the gravitational field. When the vehicle stops, it is reset to zero.

Since the work of a vehicle has, as a rule, unsteady and/or cyclic nature of motion speed change, at the first stage of approximation (anyway, within the framework of the article), let us replace the non-stationary process with the steady uniform process with a representative average motion speed. This also corresponds to the Life Cycle Assessment (LCA) technology at first stages of the formation of the corresponding assessments.

The diagram in Figure 4 allows carrying out the corresponding analysis of the energy efficiency, since average values for average motion speeds within life cycles are plotted on two axes of ordinates.

On top of that, the red line represents the limit for the feasibility of transportation and the ability to provide transportation services; any points below the line mean that the energy set in the transport system is not enough even for the motion of one absolutized transport object, not to mention the energy consumption for transfer of transport containers, i.e. a vehicle.

This is the absolute lower limit, independent on the transport mode and corresponding to the transportation service $S$ in equation (1). Even a quick overview of the diagram canvas in Figure 4 allows noting several factors. With the transition to high speeds of motion, the energy efficiency of transport modes increases (cars: 0.05-0.20, railway trains: $0.15-0.30$, aircrafts: $0.40-0.60$ ).

At the same time, too high energy efficiency of highspeed trains (points 14-17) gives pause on reflection on shallow coverage (by the observer) of energy processes and products in the chain of the creation of these vehicles.

\section{Conclusion}

The sequence of research activities of the author allowed forming a technique for transport energy efficiency assessment on the basis of the life cycle with the attraction of the Bartini Transfer entity.

Main elements of the technique are the following: 1) assertion of the necessity to correlate (compare) the amount of energy to the absolutized transfer of a transport object with the life-cycle Cumulative Energy Demand (CED); 2) selection of the Bartini Transfer entity (and the corresponding cell of the Bartini table) for the mentioned correlation; 3) use of the Tiguntsev model for calculations of the kinetic and potential energy for the motion of an absolutized transport object in the gravitational field; 4) construction of a diagram with axes Speed $V$ and Specific CED; 5) carrying out of the analysis in the field of the VCED diagram for the comparison of the amount of energy to the transfer of an absolutized transport object with the transport system CED for such transportation.

It shall be noted that the technique requires further development both in terms of more accurate determination and interrelation of its main functionalities, and in terms of the particularization of analytical activities. 


\section{References}

Aleinikov, A. (2007). Nine new laws of conservation: future science horizons. In: Proceedings of the Allied Academies International Conference, 6(2), pp. 5-10.

Aseev, A.G. (2012). Glamour and Emptiness of our world. Available at: http://noocosmology.com/article/glamour_and_emptiness_of_our_world.html (accessed on: 30.09.2017)

Bartini R.O., Kuznetsov P.G. (1974). Multiplicity in geometries and physics. In: Proceedings of the seminar "Cybernetics of electric power systems", p.11. Available at: http://www.metodolog.ru/01380/01380.html (accessed on: 30.09.2017)

Bartini, R.O. (1965). Some relations between physical constants. Reports of the Academy of Sciences of the USSR, 163 (4), pp.861-864.

Chester, M., Horvath, A. (2010). Life-cycle assessment of high-speed rail: the case of California. Environmental Research Letters, 5(1), paper ID 014003. DOI:10.1088/1748-9326/5/1/014003

Daimler AG, Mercedes-Benz Cars (2015). Life Cycle. Environmental Certificate Mercedes-Benz S-Class. Stuttgart. Available at: https://www.daimler.com/images/sustainability/produkt/new-enviromentalcertificates/daimler-umweltzertifikat-mb-s-klasse. pdf (accessed on: 30.10.2017)

Hilty, L.M., Coroama, V., Eicker, M., Ruddy, T., Müller, E. (2009). The Role of ICT in Energy Consumption and Energy Efficiency. Available at: http://s3.amazonaws.com/publicationslist.org/data/lorenz.hilty/ref-42/2009-08\%20Hilty\%20Coroama\%20et\%20 al\%20EU\%20ENSURE\%20ICT\%20Energy.pdf (accessed on: 30.10.2017)

Kotikov, Ju.G. (2001). Osnovy sistemnogo analiza transportnykh sistem [Fundamentals of system analysis for transport systems]. Saint Petersburg: Saint Petersburg State University of Architecture and Civil Engineering, p.264. (in Russian)

Kotikov, Ju.G. (2005a). Analiz energoeffektivnosti transporta s pomoshchiu izmeritelia Tran [Analysis of transport energy effectiveness using the Tran unit]. Integrated logistics, 3, pp. 15-20. (in Russian)

Kotikov, Ju.G. (2005b). Energeticheskaia effektivnost avtotransportnogo kompleksa [Energy effectiveness of the automotive transportation system]. Bulletin of Transport, 4, pp. 37-39. (in Russian)

Kotikov, Ju.G. (2017a). Estimation of Transportation Energy Efficiency by Bartini Criterion L6T-4. Architecture and Engineering, 2 (2), pp.15-19. DOI: 10.23968/2500-0055-2017-2-2-15-19.

Kotikov, Ju.G. (2017b). Calculation of Freight Rail Transport Energy Efficiency by Bartini Criterion L6T-4. Architecture and Engineering, 2 (3), pp. 21-25. DOI: 10.23968/2500-0055-2017-2-3-21-25.

Kotikov, Ju.G., Lozhkin, V.N. (2006). Transportnaya energetika [Transport power energy]. Moscow: Publishing Center "Academia", p.272. (in Russian)

Mithraratne, N. (2011). Lifetime liabilities of land transport using road and rail infrastructure. http://www.nzta.govt.nz/assets/ resources/research/reports/462/docs/462.pdf (accessed on: 30.10.2017).

Oak Ridge National Laboratory (2016). Transportation Energy Data Book, Edition 35. Available at: http://cta.ornl.gov/data/ tedb35/Edition35_Chapter01.pdf (accessed on: 07.09.2017)

Obraztsova, R.I., Kuznetsov, P.G., Pshenichnikov, S.B. (1997). Inzhenerno-ekonomicheskii analiz transportnykhsistem [Engineering and economic analysis of transport systems]. Novosibirsk, p.156. Available at: http://lib.uni-dubna.ru/search/files/ur_enjekan/ ur_enj-ek-an.htm (accessed on: 30.09.2017). (in Russian)

Stripple, H., Uppenberg, S. (2010). Life Cycle Assessment of Railways and Rail Transports. Available at: http://www.ivl.se/download/18.343dc99d14e8bb0f58b75d4/1445517456715/B1943.pdf (accessed on: 30.06.2017)

Technical Committee ISO/TC 207 (2006) ISO 14040:2006: Environmental management — Life cycle assessment — Principles and frame-work. Available at: http://www.pqm-online.com/assets/files/lib/std/iso_14040-2006.pdf (accessed on: 12.10.2017)

Tiguntsev, S.G. (2014). Potentcialnaia i kineticheskaia energiia pri ravnomernom gorizontalnom dvizhenii tel [Potential and kinetic energy upon the uniform horizontal motion of bodies]. Nauchno-entciklopedicheskii portal [Scientific encyclopedic portal]. Available at: http://www.russika.ru/userfiles/adm_1404275497.pdf (accessed on: 30.10.2017). (in Russian)

Tiguntsev, S.G. (2015). Ob inertcii i printcipe otnositelnosti [On inertia and principle of relativity]. Available at: http://www.bourabai.kz/tiguntzev/index.htm (accessed on: 30.10.2017). (in Russian)

U.S. Energy Information Administration. (2016). International Energy Outlook. Available at: https://www.eia.gov/outlooks/ieo/ pdf/0484(2016).pdf (accessed on: 30.09.2017)

Zhou, J., (2014). Improving the energy efficiency of high speed rail and life cycle comparison with other modes of transport. London: Imperial College London. Available at: https://www.google.ru/url?sa=t\&rct=j\&q=\&esrc=s\&source=web\&cd=1\&ved=0ahUKEwjlvMLYyarWAhUBDJoKHXnaAc0QFggnMAA\&url=https\%3A\%2F\%2Fspiral.imperial.ac.uk\%3A8443\%2Fbitstream\%2F1 0044\%2F1\%2F25066\%2F3\%2FZhou-J-2014-PhD-Thesis.pdf\&usg=AFQjCNHMI73iTD9wyjJevIVpeOs_1H9CgA (accessed on: 30.10.2017) 